\title{
Cytokine-Rich Adipose Tissue Extract Production from Water-Assisted Lipoaspirate: Methodology for Clinical Use
}

\author{
Jenny Lopez, ${ }^{1, *}$ Outi Huttala, Jertta-Riina Sarkanen,,4 ${ }^{1 / k k a}$ Kaartinen, ${ }^{2,4}$ Hannu Kuokkanen, ${ }^{2,4}$ and Timo Ylikomi ${ }^{1,4}$
}

\begin{abstract}
Proper functioning wound healing strategies are sparse. Adequate vascular formation to the injured area, as well as replacement of the volume loss, is fundamental in soft tissue repair. Tissue engineering strategies have been proposed for the treatment of these injury sites. Novel cell-free substance, human adipose tissue extract (ATE), has been previously shown to induce in vitro angiogenesis and adipogenesis and in vivo soft tissue formation. This study reports the translation of ATE preparation from laboratory to the operating room (OR). ATE samples for this study were derived from adipose tissue obtained with the water-jet assisted liposuction technique from 27 healthy patients. The variables studied included incubation time (15, 30, and $45 \mathrm{~min})$, temperature (room temperature vs. $37^{\circ} \mathrm{C}$ ), and filter type to determine the optimal method yielding the most consistent total protein content, as well as consistent and high expression of adipose-derived growth factors and cytokines, including: vascular endothelial growth factor, basic fibroblast growth factor, interleukin-6, adiponectin, leptin, and insulin-like growth factor. Following the optimization, samples were produced in the OR and tested for their sterility. No significant differences were observed when comparing extract incubation time points or incubation temperature. Nonetheless, when studying the different filter types used, a syringe filter with PES membrane with larger filter area showed significantly higher protein concentration $(p \leq 0.018)$. When studying the different growth factor concentrations, ELISA results showed less variation in cytokine concentrations in the OR samples with the optimized protocol. All of the OR samples were tested sterile. The devised protocol is an easy and reproducible OR-ready method for ATE generation. As an attractive source of growth factors, ATE is a promising alternative in the vast field of tissue engineering. Its clinical applications include volume replacement as a complement to fillers and improvement of the permanence of fat grafts and wound healing, among other bioactive functions.
\end{abstract}

Keywords: acellular biological matrices; adipose; angiogenesis and vasculogenesis; biomedical engineering; growth factors

\section{Introduction}

Currently, the major challenge in tissue engineering lies not only in the high costs of material production and safety of the biomaterial used but also most importantly in the lack of efficacy in promoting vascular formation and soft-tissue replacement. ${ }^{1-4}$ In particular, neovascularization induction is a major obstacle for developing tissue engineering strategies. ${ }^{5-9}$

Mature human adipose tissue, considered an endocrine entity on its own, is a known source of growth

\footnotetext{
${ }^{1}$ Department of Cell Biology, School of Medicine, University of Tampere, Tampere, Finland.

${ }^{2}$ Department of Plastic Surgery, Unit of Musculoskeletal Diseases, Tampere University Hospital, Pirkanmaa Hospital District, Tampere, Finland.

${ }^{3}$ FICAM, Finnish Centre for Alternative Methods, School of Medicine, University of Tampere, Tampere, Finland.

${ }^{4}$ Science Center, Pirkanmaa Hospital District, Finland.

*Address correspondence to: Jenny Lopez, MD, Department of Cell Biology, School of Medicine, University of Tampere, PL100, 33014 Tampere, Finland, E-mail: jenny_lopez1978@hotmail.com
}

(C) Jenny Lopez et al. 2016; Published by Mary Ann Liebert, Inc. This Open Access article is distributed under the terms of the Creative Commons License (http://creativecommons.org/licenses/by/4.0), which permits unrestricted use, distribution, and reproduction in any medium, provided the original work is properly credited. 
and differentiation promoting factors. ${ }^{10-16}$ These growth factors have the ability to induce proliferation, migration, and differentiation of various cell lines. ${ }^{13-17}$ Extensive functions and clinical applications of growth factors are well reported in the literature. ${ }^{18-24}$ Adipose tissue is an excellent source of adipose stem cells in addition to the adipose-derived growth factors, ${ }^{11,25-30}$ and human adipose tissue is easily available through liposuction.

We have previously developed an acellular bioactive extract from mature adipose tissue, proven to contain important adipose tissue cytokines, including vascular endothelial growth factor (VEGF), basic fibroblast growth factor beta $(\mathrm{FGF} \beta)$, interleukin 6 (IL-6), insulin-like growth factor 1 (IGF-1), adiponectin, and angiogenin, among others. ${ }^{31,32}$ This extract demonstrates a unique capacity of inducing angiogenesis and adipogenesis. ${ }^{31}$

Animal experimental models indicated that, in combination with hydrogel, this adipose tissue extract (ATE) promoted neovascularization and soft tissue expansion. In addition, it was shown that the permanence of the effect of the extract remained for 9 months. Furthermore, during short- and long-term follow-up, no hypersensitivity or foreign body reactions were reported with human extract in rat experimental models. ${ }^{32}$

When aiming at using this autologous extract in clinical studies, the development of a straightforward and reliable method for operation room preparation is essential. ATE was previously produced from solid mature adipose tissue and shown to be bioactive in vitro and in vivo. ${ }^{31,32}$ In the current study, ATE was produced from lipoaspirate material. This simple surgical procedure and operating room (OR) preparation would make ATE an attractive source of multiple growth factors and cytokines with a plethora of future applications. ${ }^{32}$

In vitro, these growth factors have demonstrated the induction and differentiation of adipocytes, endothelial cells, keratinocytes, chondrocytes, and osteoblasts, among others involved in tissue regeneration. ${ }^{31,33,34}$ The potential of ATE for different applications holds value in areas where soft tissue formation and volume are required, especially in volume loss and potentially for optimizing fat grafting permanence. ${ }^{32}$

In this study, the optimal method of human fat extract preparation was investigated with different variables, such as incubation time, temperature, and filter type. These characteristics were considered key when transferring the methodology from the laboratory to the OR while meeting the clinical and surgical standards. The goal was to develop a protocol that meets clinical standards that allow the surgeon to prepare the ATE in the OR for immediate application and translate the ATE laboratory protocol for clinical therapeutic use.

\section{Materials and Methods \\ Ethical aspects}

The study was conducted according to the Declaration of Helsinki, the European Guidelines on Good Clinical Practice, and was approved by the Ethics Committee of the Pirkanmaa Hospital District, Tampere, Finland (R03058). The human adipose tissue samples were obtained from surgical operations with informed consents at the Tampere University Hospital, Tampere, Finland.

\section{Samples}

Human adipose tissue samples were obtained through the water-assisted liposuction technique (body-jet; Human Med AG, Germany) and processed under sterile conditions. A total of 27 patients were included in the study. The main indications for liposuction in these patients were fat grafting and body contouring. Exclusion criteria for the donors were patients receiving hormonal therapy, after cancer ablative surgery, active cancer, recent chemotherapy treatment, and comorbidities that contraindicated the surgery. All surgeries were uneventful, and no complications were reported. All tested samples were from female patients, and their mean age, weight, and body mass index are listed in Table 1. Lipoaspiration was performed in the abdominal subcutaneous tissue in $76.2 \%$ of the patients, from the flank region in $19 \%$ and from the thigh in $4.7 \%$.

\section{Lipoaspiration procedure}

Liposuctions were performed under general or spinal anesthesia using the water-assisted technique (bodyjet, Human Med AG, Germany). Tumescent solution containing $1 \mathrm{mg}$ of adrenaline and $250 \mathrm{mg}$ of lidocaine per $1000 \mathrm{~mL}$ saline was infiltrated. The pressure of infiltration and suction was done at a range of 2 or 3 (50

Table 1. Patient Demographics

\begin{tabular}{lcc}
\hline & Mean value & Range \\
\hline Age & 51.95 & $33-68$ \\
Weight & 77.1 & $57-94$ \\
Body mass index & 28.1 & $21-38$ \\
\hline
\end{tabular}




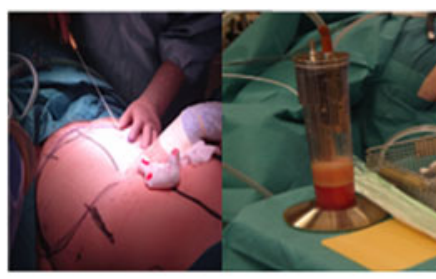

STEP 1: Liposuction and fat collection

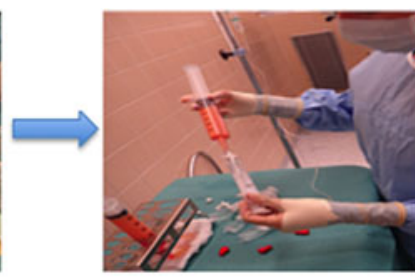

STEP 2: Addition of Ringer solution

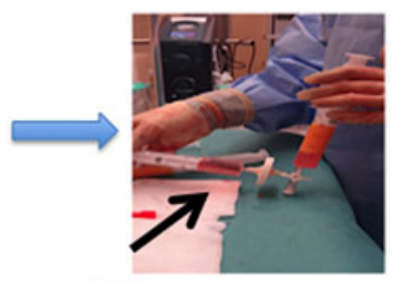

ATE

FIG. 1. Steps for ATE preparation. Step 1, Liposuction and collection of adipose tissue with water-assisted liposuction. Step 2, Transfer of fat into syringes and addition of Ringer solution. Step 3, 30 min incubation and filtration to produce sterile ATE, which is ready for clinical use. ATE, adipose tissue extract.

or 70 bar). Lipoaspiration was performed under $-400 \mathrm{mbar}$ pressure. As a guide, range 2 is equivalent to $110 \mathrm{~mL} / \mathrm{min}$ and a range 3 to $130 \mathrm{~mL} / \mathrm{min}$ of tumescent jet emission. Adipose tissue collection was done under a sterile environment into a canister (LipoCollector, Human Med, Germany) and transferred to $50 \mathrm{~mL}$ syringes. The amount of fat aspirated for sampling varied from 40 to $100 \mathrm{~mL}$ per patient.

\section{Production of ATE in the laboratory}

In the laboratory, ATE was produced by adding Ringer lactate (Baxter Healthcare Corporation, Helsinki, Finland) to the adipose tissue sample at an approximate ratio of 1:1 and then processed according to the different study variables. Incubation was performed at $37^{\circ} \mathrm{C}$ water bath or at room temperature (RT). The incubation times studied were 15,30 , or $45 \mathrm{~min}$. After incubation, the samples were sterile filtered with different $0.2 \mu \mathrm{m}$ pore size syringe filters (Acrodisc ${ }^{\circledR}$ filter, polyethersulfone PES membrane [PALL Life Sciences, New York]; Minisart NML filter, cellulose acetate membrane [Sartorius AG, Germany]; Filtropur S Plus filter, cellulose acetate membrane [Sarstedt \& Co, Germany]; and Millex GP filter, PES membrane [Merck, Millipore, Germany]). Once filtered, the ATE was stored at $-20^{\circ} \mathrm{C}$ until sample analysis.

\section{Production of ATE in the OR}

ATE production was performed on a separate sterile bench in the OR. After performing the lipoaspiration, the adipose tissue was gently mixed with prewarmed $\left(37^{\circ} \mathrm{C}\right)$ Ringer lactate solution at an approximate ratio of 1:1. The mixture was incubated for $30 \mathrm{~min}$ at RT. The lower layer containing the Ringer lactate solution was passed through a sterile filter and frozen at $-20^{\circ} \mathrm{C}$ until further use. The preparation method of ATE is summarized in Figure 1. ATE samples have previously been shown to induce adipogenesis from $200 \mu \mathrm{g} / \mathrm{mL}$ upwards in cell culture. ${ }^{31,32}$ Thus, total protein concentration of $200 \mu \mathrm{g} / \mathrm{mL}$ was selected as the lowest acceptance limit of ATE samples. ATE samples prepared in the laboratory and OR originated from different donors.

\section{Sterility test of OR samples}

Sterility test was performed from six ATE samples prepared in the OR. Approximately, $2 \mathrm{~mL}$ of ATE was added per BacT/ALERT system (bioMérieux SA, France) bottle. Aerobic BacT/ALERT SA and anaerobic bacteria testing BacT/ALERT SN (i.e., gram-positive and gramnegative bacteria and yeast) were performed for each ATE sample. Samples were cultured in BacT/ALERT 3D (bioMérieux SA) for 10 days before analyzing bacterial growth. "Negative" results in the system indicated that there was no bacterial or yeast growth.

\section{Measurement of protein concentration}

Total protein content of the samples was measured using Pierce ${ }^{\mathrm{TM}}$ BCA Protein Assay Kit (Thermo Scientific, Waltham, MA) according to manufacturer's instructions using bovine serum albumin (BSA) as a standard. Results were measured after $30 \mathrm{~min}$ incubation at $37^{\circ} \mathrm{C}$ at $562 \mathrm{~nm}$ with Varioskan ${ }^{\mathrm{TM}}$ Flash Multimode Reader (Thermo Scientific).

\section{Measurement of growth factor concentration}

Extract samples were tested with colorimetric sandwich ELISA, Custom made ELISA strips $\left(\right.$ Signosis ${ }^{\circledR}$, Santa Clara, CA). The following cytokines were evaluated: VEGF, tumor necrosis factor alpha (TNF $\alpha)$, interferon 
gamma (IFN $\gamma$ ), granulocyte colony stimulating factor (G$\mathrm{CSF}$ ), granulocyte macrophage colony stimulating factor (GM-CSF), IL-6, IL-8, IGF-1, IL- $1 \alpha$, FGF $\beta$, resistin, macrophage inflammatory protein (MIP-1), adiponectin, leptin, and rantes. Protein standards for custom human cytokine ELISA Strip (Signosis) were used with concentrations of 2 and $1 \mathrm{ng} / \mathrm{mL}$. The ELISA strips were used according to manufacturer's instructions as follows. To each well, $100 \mu \mathrm{L}$ of the studied ATE batch was added and incubated for $1 \mathrm{~h}$ with gentle shaking in RT. The liquid was then aspirated from each well and the wells were washed thrice with $200 \mu \mathrm{L}$ of assay wash buffer per well. Subsequently, $100 \mu \mathrm{L}$ of Streptavidin-HRP conjugate diluted 1:200 in diluent buffer was added to each well and incubated for $45 \mathrm{~min}$ at RT under gentle shaking. After incubation, the wells were washed thrice with $200 \mu \mathrm{L}$ of washing buffer. One hundred microliters of substrate was added in each well and then incubated between 5 and $30 \mathrm{~min}$ per cytokine. The reaction was ended with the addition of $50 \mu \mathrm{L}$ of stop solution to each well row simultaneously and detecting a visible color change of the standard. The optical density was determined at $450 \mathrm{~nm}$ with Varioskan Flash multimode reader (Thermo Scientific).

\section{Statistical analyses}

Statistical analyses were performed and graphs processed with GraphPad Prism 5.0 (GraphPad Software, Inc., San Diego, CA). The results were reported as mean $\pm \mathrm{SD}$, and differences were considered significant when $p<0.05^{*}, p<0.01^{* *}$, and $p<0.001^{* * *}$. Results of total protein concentration in incubation temperature comparison and laboratory versus OR production of ATE were analyzed with student's $t$-test and two-tailed posttest. The analyses of incubation time and filter type used were performed using One-way ANOVA with Tukey's posttest. The relationship of growth factor concentrations in OR samples to laboratory samples was calculated with Pearson's correlation and results depicted as $r$ values.

\section{Results}

The effect of incubation temperature

The effect of incubation temperature on ATE protein concentration was studied with a cellulose acetate membrane filter (Sarstedt, Germany) used in our previous in vitro studies. ${ }^{31}$ No significant difference in total protein concentration was observed between RT incubation and $37^{\circ} \mathrm{C}$ water bath incubation (Fig. 2A). However, there was a slightly higher concentration of total protein in water bath incubated samples compared to RT incubated samples.

\section{The effect of incubation time}

Incubation times of 15,30 , and $45 \mathrm{~min}$ were studied to determine the shortest time for OR ATE extraction (considering possible immediate clinical use) in reference to protein yield. Incubation was performed in RT and the extract passed through a cellulose acetate membrane filter (Sarstedt, Germany). ${ }^{31}$ The total protein concentration between the time points did not differ significantly (multiplicity adjusted $p \geq 0.992$, Fig. 2B), but the protein yield showed less variation and slightly higher values in the 30 min time point.

\section{Filter testing}

To estimate whether the protein yield varied among different filter membranes, four different $0.2 \mu \mathrm{m}$ filters were selected. ATE was produced at $30 \mathrm{~min}$ incubation at RT and subsequently strained through the filters. Close to $1000 \mu \mathrm{g} / \mathrm{mL}$ protein was obtained with all filters, but with polyethylene sulfone (PES) membrane and largest surface area, showed a significantly higher protein yield (multiplicity adjusted $p \leq 0.018$ ) compared to the other filters (Fig. 3).

\section{Transfer of the extraction protocol}

from laboratory to the $\mathrm{OR}$

To transfer the laboratory methodology to the OR, ATE was produced at RT incubation for $30 \mathrm{~min}$ and subsequently filtered with PES membrane. The results in Figure 4 show that the samples produced in the laboratory had greater deviation yet higher protein concentrations. However, these were not significantly higher than the OR samples ( $p$ 0.0730, medians 1210 and 321.5, respectively).

\section{Growth factor content of the samples}

To control the quality and assure the bioactivity of the samples, growth factor measurements of both laboratory and OR samples were studied. The results show that the growth factor yields were comparable between the samples produced in the laboratory and those from the OR (Fig. 5) although the correlations varied between the growth factors (Fig. 5). The samples had less variation when performed in the OR with the optimized protocol (Fig. 5). Most of the growth factors correlated well with laboratory samples and in addition, VEGF (also higher $\mathrm{CV}$ ) and G-CSF produced higher mean growth factor concentrations in the OR with the optimized protocol. 

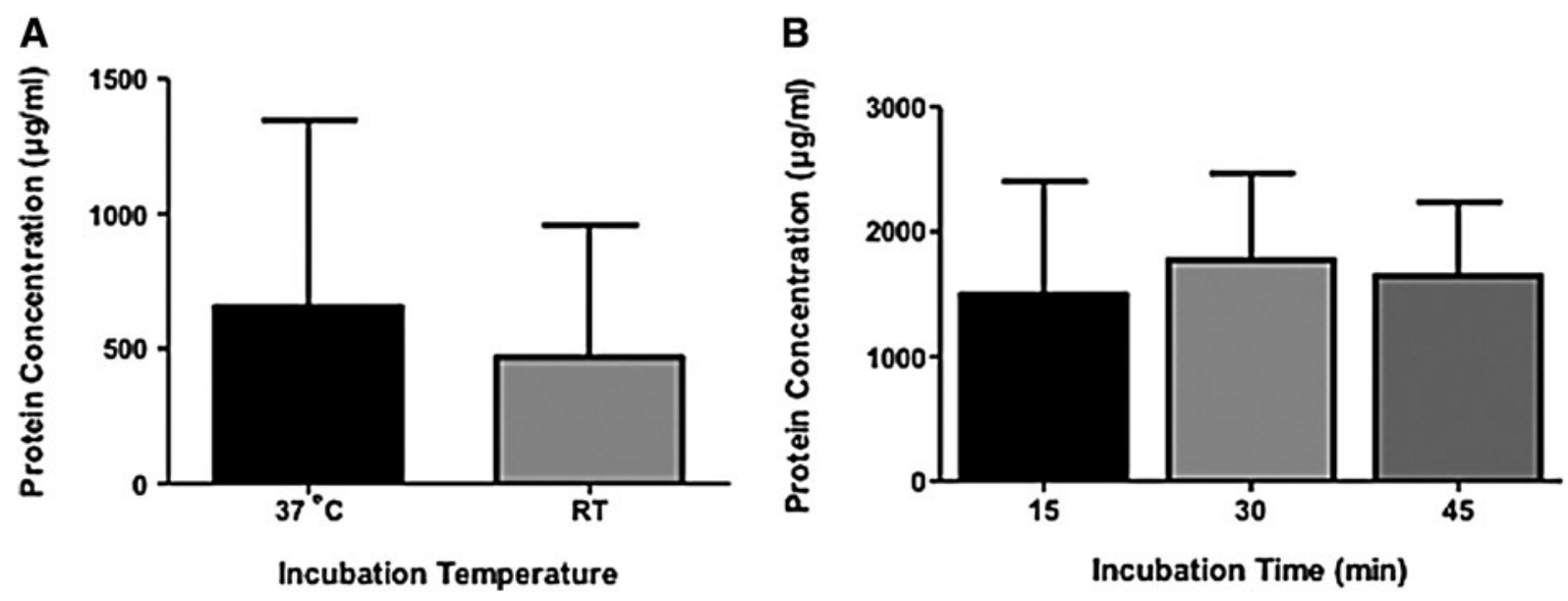

FIG. 2. (A) Protein concentration obtained in $37^{\circ} \mathrm{C}$ and RT incubation. Comparison of total protein content of the ATE samples in different incubation temperatures. ATE was incubated for $30 \mathrm{~min}$ in $37^{\circ} \mathrm{C}$ or RT and filtered with cellulose acetate Filter 3 . No significant difference was observed between incubation temperatures when statistically evaluated with student's $t$-test with two-tailed posttest $(p 0.7207)$ and $n=3$. (B) Protein concentrations obtained with 15, 30, and 45 min incubation. Comparison of total protein content of the ATE samples with incubation times of 15, 30, and $45 \mathrm{~min}$. ATE was produced in equal conditions except for incubation time, that is, incubation was performed in RT and filtered with Filter 3. No significant difference was observed between incubation times when statistically evaluated with one-way ANOVA with Tukey's posttest ( $p$ 0.9923) and $n=3$. RT, room temperature.

\section{Sterility test}

A sterility test was performed to ensure asepsis of the samples in the OR. All ATE samples were negative for bacterial growth in aerobic and anaerobic media.

\section{Discussion}

One of the main challenges in tissue engineering is to discover a bioactive source of growth factors with regenerating properties while accelerating local action, enhancing volume replacement and stimulating the growth of multiple cell lines. ${ }^{13,35-38}$ The most important feature is to rapidly induce tissue neovascularization to avoid hypoxia and ischemia. ${ }^{39-43}$ Ideally, this bioactive material should also be cost beneficial, easy to prepare, and reproducible. In our previous studies, we have been able to isolate a novel cell-free bioactive substance, ATE, which not only induces angiogenesis and adipogenesis in vitro and in experimental models but also is rich in growth factors. ${ }^{31,32}$ The advantage of the current growth factor material is that as it does not contain cells, it should have less immune reactions and its allogeneic use could be possible. This would ease its clinical use. As ATE is a large mixture of growth factors, it has potential for better bioactivity. Clinicians are still struggling to improve adipose tissue transfer viability and working on ways to improve wound healing, scenarios that would benefit from growth factor use.

The main aim of the current study was to transfer the method of obtaining adipose tissue growth factors from the laboratory to the OR for later successful clinical use. ATE has previously shown to induce soft tissue formation when incorporated into hyaluronic acid and is therefore a very promising material for soft tissue replacement and soft tissue healing. ${ }^{31,32}$ The authors compared previously used parameters, protein yield, and growth factor content and focused on modifiable parameters when transferring the methodology from the laboratory to the clinic. The variables contemplated in this study were incubation time, incubation temperature, and filter type. During the translation process of ATE production from the laboratory to the OR, there are high clinical demands to be met not only from the clinical materials used but also to make this a simple method from surgical staff s point of view. Because in previous studies, ${ }^{31,32}$ whole solid fat was processed in the laboratory to obtain ATE, it was crucial to 


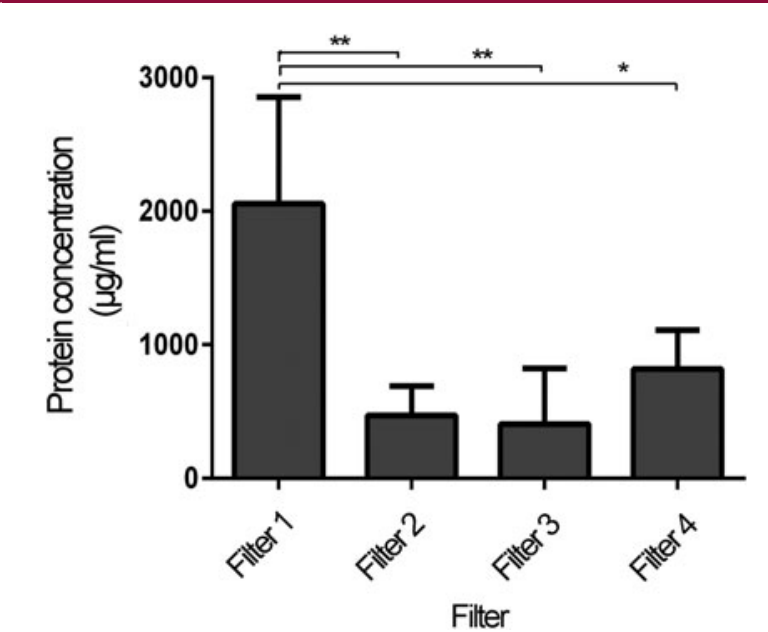

FIG. 3. Protein concentrations obtained with four different filters. Comparison of total protein concentration when ATE was produced with 30 min incubation at RT using four distinct filters; PES Filter $1\left(7.5 \mathrm{~cm}^{2}\right)$, cellulose acetate Filter 2 $\left(6.2 \mathrm{~cm}^{2}\right)$, cellulose acetate Filter $3\left(5.3 \mathrm{~cm}^{2}\right)$, and PES Filter $4\left(4.5 \mathrm{~cm}^{2}\right)$. Statistical analysis was performed with One-way ANOVA with Tukey's posttest, $p<0.05^{*}$ and $p<0.01^{* *}$ and $n=4$.

discover an easy method that would preserve an adequate protein yield.

This transfer method is not only important but also complicated and the impact of these variables had to be determined. Therefore, our aim was to maintain growth factor yields comparable to our previous studies, in a repeatable scenario. Moreover, our original studies were performed with solid adipose tissue that underwent processing, so we verified that the resulting ATE would, in fact, yield similar results when originating from lipoaspirates. As a lipoaspiration method, we used the water-assisted technique, which has been standardly used in our clinic due to its simplicity, and demonstrated adipose tissue viability preservation. ${ }^{44}$ Although the technique uses the power of water at certain pressures, it is gentle enough to preserve adipocytes with minimal tissue injury or blood loss. In addition, patient recovery is quicker and morbidity lower than traditional liposuction. ${ }^{45,46}$

In the current study, we optimized the preparation protocol of ATE to translate the production from the laboratory to the OR, studying three main variables. To begin with, incubation time is important consider-

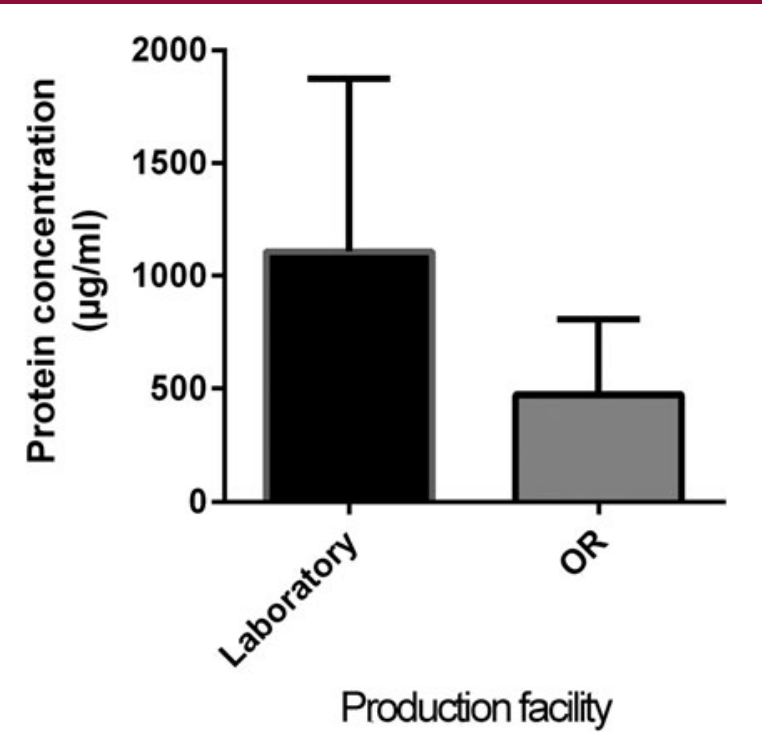

FIG. 4. Protein concentrations obtained in $O R$ versus laboratory. Comparison of total protein content between the ATE samples produced in laboratory and those produced in OR. ATE was incubated for $30 \mathrm{~min}$ in RT and filtered with PES Filter 1. No significant difference was observed between the total protein of the two production conditions as evaluated by student's $t$-test with two-tailed posttest ( $p$ 0.0922) and $n \geq 6$. OR, operating room.

ing the time the patient was in surgery under local, spinal, or general anesthesia. In ideal conditions, surgical time should be as short as possible to prevent patient perioperative complications and this is the reason why the time points of 15,30 , and 45 min were selected. Furthermore, because original ATE samples were incubated either in water bath or $37^{\circ} \mathrm{C}$ incubator, we found that comparing it to RT would offer the surgeon an easier method to produce ATE. In relation to the filter, during the translation process, we noticed that operating theaters use a variety of materials of high clinical standard demands. In our laboratory studies, we used filters that were not applicable to the OR environment; therefore, the challenge was to test those that did meet these standards while preserving the protein yield. The protocol was tested with four different filters with PES and cellulose acetate membranes. We noticed that although a larger filter area played a role, it seemed that the hydrophilic low-protein binding nature of the PES filter demonstrated advantages. Different to 


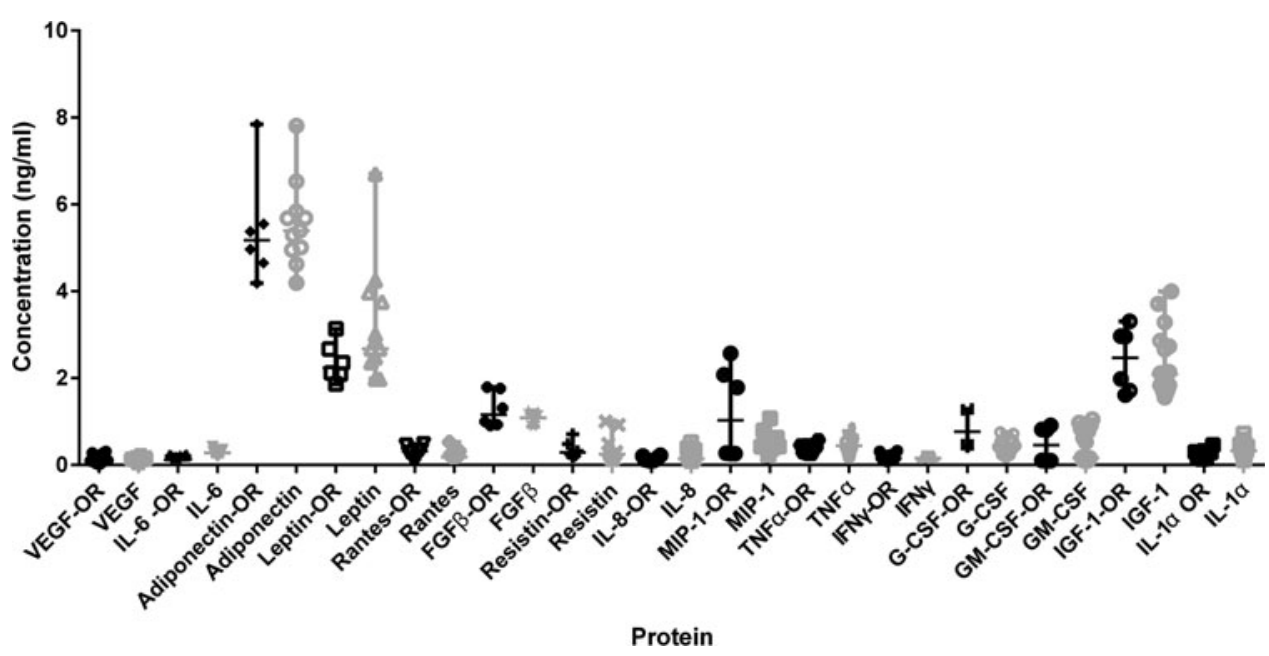

FIG. 5. Specific protein concentrations in OR vs. laboratory. Analysis of 16 different adipokines in samples produced in laboratory in optimization phase versus samples produced in OR after optimization. Adipokines analyzed were VEGF, IL-6, adiponectin, leptin, rantes, FGF $\beta$, resistin, IL-8, MIP-1, TNF $\alpha$, IFN $\gamma$, G-CSF, GM-CSF, IGF-1 and IL- $1 \alpha$. Results depicted as mean \pm SD, $n \geq 6$.

previous publications, we used lipoaspirate material that contains particles that easily clog filters, which also led us to choose the adequate PES filter type. However, we recognize that interpersonal variations play a great influence in the final protein yield. The optimization showed to reduce the variation between the samples and the specific growth factor concentrations were not lost during the protocol modifications. In addition, the samples produced in the OR passed the sterility tests performed.

By studying the effect of incubation temperature (RT vs. $37^{\circ} \mathrm{C}$ ) and time $(15,30$, and $45 \mathrm{~min})$, we showed that the protocol is flexible enough to be performed in the busy OR setting without compromising the quality of the product.

When studying the protein yield, we observed that adequate amounts were obtained in short incubation times $(15,30$, and $45 \mathrm{~min}$ ); yet we settled for $30 \mathrm{~min}$ as slightly higher protein concentrations were achieved from this time point onward. Interestingly, temperature variations did not seem to affect total protein and cytokine yields. We noticed that although the filter characteristics may play a role, sample handling had an important effect on the protein yield. Samples that had to be neglected from the study (protein concentration $<200 \mathrm{ng} / \mathrm{mL}$, four samples) were performed in the laboratory, and thus, the time from the surgery to the preparation of ATE varied. This was based on previous studies where bioactivity was proven above this concentration of protein. ${ }^{31,32}$ Nonetheless, the filter material or surface area of the filter may also have an impact on the protein concentration and, therefore, on the feasibility of the ATE production procedure.

We observed lower variations in growth factor and cytokine measurements in the samples produced in OR compared with the laboratory samples. It is well known that interindividual differences in cytokine concentrations from freshly prepared primary cells are usually much higher than the variations seen with repeated preparations of the same donor. ${ }^{47}$ There is an inevitable patient-related variation due to the effects of body mass index, age, weight, comorbidity, and liposuction site that may affect protein yield, but the optimization of the protocol was successful in decreasing the sample-to-sample variation. The growth factor results are also in concordance with our previous studies at 1 -h incubation. ${ }^{32}$

Since ATE is prepared from autologous adipose tissue, theoretically there are no risks for disease transmission, immunogenic reactions, or cancer. This solution is eluted from the filter, providing a cell-free enriched fraction of biologically active mediators (VEGF, IGF-1, etc.), most of which are key in wound healing. The most abundant adipokines released by adipocytes, leptin, and adiponectin, ${ }^{48,49}$ as well as IGF-I, were also predominant in this study. Inflammation- 
related factors observed by other investigators included leptin, resistin, adiponectin, TNF $\alpha$, IL-6, and plasminogen activator inhibitor- $1 .^{50}$ In obese individuals, there is an increased expression of pro-inflammatory cytokines such as TNF $\alpha$, TGF $\beta$, and IL- $6 .{ }^{51}$ In our previous studies, FGF $\beta$, IGF-I, and IL- 6 seemed to suggest the adipogenic and angiogenic potential of ATE. ${ }^{31,32}$ VEGF initiates angiogenesis, ${ }^{52}$ while IGF-1 and FGF $\beta$ promote wound healing. ${ }^{53}$ However, determining the optimal growth factor cocktail for adipogenesis and angiogenesis is challenging. Therefore, both the total protein concentration measurement and a set of growth factors measured should be kept as a quality assurance method also in further studies regarding ATE.

It is the authors' belief that the main point of this study was to conserve the growth factor yield when transferring from a laboratory methodology to an OR setting. Variations in growth factor concentrations are multifactorial, but we believe that interpatient variations play an important role. Therefore, we focused on maintaining protein yield compared to previous publications $s^{31,32}$ that demonstrated proven biological activity.

The protocol optimization showed that ATE is easily produced in the OR with a simplified method that preserves sterility and lays the foundation to implement ATE into the clinical setting. One of the major goals of this development process was to find acceptable range of variability for an optimal ATE preparation, without compromising the time pressure of a surgical setting. A distinct advantage of ATE is that it not only is prepared freshly from each patient for immediate use (e.g., treat wounds) but also that it can be frozen and used for sequential treatments. This eliminates the need for consecutive surgeries substantially reducing the surgeon's workload and also increasing patient comfort. ${ }^{47}$ Material OR requirements for ATE preparation are minimal and the need for centrifugation or activation is bypassed. The fact that sufficient protein content can be obtained in an even shorter incubation time than studied earlier ${ }^{32}$ and under RT makes ATE a more attractive choice for clinicians compared to currently used products.

Orthobiologics is a relatively new science that involves application of naturally found materials from biological sources (e.g., cell-based therapies) and offers exciting new possibilities to promote and accelerate bone and soft tissue healing. ${ }^{54,55}$ The goal of this discipline is to enhance the body's innate ability to repair and regenerate. ${ }^{55}$ In fact, the inductive microenvironment has previously shown to en- hance migration of adipose stromal cells in the surrounding tissue and stimulate the cells to differentiate into mature adipocytes. ${ }^{56}$ Growth factors are known to play essential roles in wound repair and may hold the key to successful healing. However, the use of single cytokines has generated disappointing results compared to a combination of these. ${ }^{47,57}$ Therefore, it is evident that wound healing is a very complex process that relies on the harmonious action of a myriad of growth factors. This is a fundamental principle in wound healing. ${ }^{47}$ The use of secretory factors from adipose tissue to influence the wound microenvironment may be a feasible approach to develop topical applications for quicker repair. ${ }^{58} \mathrm{We}$ suggest the use of adipose tissue secretome to produce an extract rich in cytokines for topical application of wounds, rather than using the difficult process of enriching the patients' stem cells in vitro. ${ }^{58}$ Burdensome steps, including the use of collagenase for digestion of tissue to isolate stem cells, would be obviated when generating ATE, an important advantage in the clinical setting. ${ }^{58}$ To date, adipose tissue is already used as an active bio dressing to treat wounds with promising wound healing results. ${ }^{58,59}$ Similarly, adipose tissue and its secretome have positively influenced wound healing and tissue regeneration. ${ }^{60,61}$ In fact, the speed and quality of wound healing have been enhanced significantly in wounds treated with adipose tissue-derived factors. ${ }^{58,60}$ In vitro, the conditioned medium of adipose tissue composed of a multitude of adipokines and growth factors, proved to potently induce the proliferation of adipose stem cells and endothelial cells, comparable to the conditioned medium of stem cells. ${ }^{59,62}$

The potential clinical use of ATE is currently under study in different clinical applications where growth factor may be required to enhance tissue vascularization, healing, cell migration, growth, and proliferation. The use of ATE would grant the benefits of a cell-free approach and would, therefore, have a more extended scope, not just limited to autologous application. ${ }^{58}$ Furthermore, it would make the production of an offthe-shelf product according to good manufacturing practice much easier. Especially for the potential clinical applications of adipose tissue, the effect of its secretome needs to be investigated thoroughly. ${ }^{58}$ In addition, the proangiogenic effect reported in this study may pose as an attractive starting point for investigating the potential impact of adipose tissue secretory factors on neovascularization in several tissue regeneration applications. 


\section{Conclusion}

ATE is a very promising bioactive agent for a plethora of clinical uses. The relative ease of preparation, applicability in the clinical setting, favorable safety profile, and possible beneficial outcome make ATE a promising therapeutic approach for future regenerative treatments. It is easy to obtain, inexpensive, and by being autologous and cellfree, it is minimizing common problems of tissue engineering. Its proven adipogenic and angiogenic properties, along with being an abundant source of growth factors, make ATE an appealing microenvironment for cell proliferation, migration, and differentiation. Under these circumstances, any clinical scenario in need of tissue volume addition, wound healing, and adequate vascularization would benefit from ATE. The consistent protein and growth factor concentrations prove the repeatability of the method, and thus, the extract production method can be successfully produced in the OR environment and is now ready for clinical research.

\section{Acknowledgments}

We thank the healthcare staff at Tampere University Hospital, as well as the patients, for their collaboration concerning adipose tissue sample donations. The authors acknowledge Risto Vuento, $\mathrm{MD}, \mathrm{PhD}$, and the staff at Fimlab Laboratories Oy for conducting the sterility testing on the samples. At the University of Tampere, the authors thank Ms. Sari Leinonen and Ms. Hilkka Mäkinen for their excellent technical assistance. This study was financially supported by the Competitive State Research Financing of the Expert Responsibility area of Tampere University Hospital, grant 9R025, Orion-Farmos research foundation, and the Finnish Funding Agency for Technology and Innovation (TEKES). Additional funding for the project was provided by The Diabetes Research Foundation.

\section{Author Disclosure Statement}

\section{Patent pending WO2010026299A1.}

\section{References}

1. Clark RA, Ghosh K, Tonnesen MG. Tissue engineering for cutaneous wounds. J Invest Dermatol. 2007;127:1018-1029.

2. Elçin YM, Dixit V, Gitnick G. Extensive in vivo angiogenesis following controlled release of human vascular endothelial cell growth factor: implications for tissue engineering and wound healing. Artif Organs. 2001;25:558-565.

3. Jain RK, Au P, Tam J, et al. Engineering vascularized tissue. Nat Biotechnol. 2005;23:821-823.

4. Place ES, Evans ND, Stevens, MM. Complexity in biomaterials for tissue engineering. Nat Mater. 2009;8:457-470.

5. Wong HK, Ivan Lam CR, Wen F, et al. Novel method to improve vascularization of tissue engineered constructs with biodegradable fibers. Biofabrication. 2016;7:015004.
6. Choi YD, Shin HS, Mok JO. Impaired survival of autologous fat grafts by diabetes mellitus in an animal model: a pilot study. Aesthet Surg J. 2014;34:168-174.

7. Hamed S, Ben-Nun O, Egozi D, et al. Treating fat grafts with human endothelial progenitor cells promotes their vascularization and improves their survival in diabetes mellitus. Plast Reconstr Surg. 2012;130:801-812.

8. Falanga V. Wound healing and its impairment in the diabetic foot. Lancet. 2005;366:1736-1743.

9. Brem H, Tomic-Canic M. Cellular and molecular basis of wound healing in diabetes. J Clin Invest. 2007;117:1219-1222.

10. Kershaw EE, Flier FS. Adipose tissue as an endocrine organ. J Clin Endocrinol Metab. 2004;89:2548-2556.

11. Kilroy GE, Foster SJ, Wu X, et al. Cytokine profile of human adiposederived stem cells: expression of angiogenic, hematopoietic, and proinflammatory factors. J Cell Physiol. 2007;212:702-709.

12. Rehman J, Li J, Orschell CM, et al. Peripheral blood "endothelial progenitor cells" are derived from monocyte/macrophages and secrete angiogenic growth factors. Circulation. 2001;107:1164-1169.

13. Rehman J, Traktuev D, Li J, et al. Secretion of angiogenic and antiapoptotic factors by human adipose stromal cells. Circulation. 2004;109:1292-1298.

14. Traktuev D, Merfeld-Clauss S, Li J, et al. A population of multipotent CD34positive adipose stromal cells share pericyte and mesenchymal surface markers, reside in a periendothelial location, and stabilize endothelial networks. Cir Res. 2008;102:77-85.

15. Trayhurn P, Beattie JH. Physiological role of adipose tissue: white adipose tissue as an endocrine and secretory organ. Proc Nutr Soc. 2001;60:329339.

16. Trayhurn P. Endocrine and signaling role of adipose tissue: new perspectives on fat. Acta Physiol Scand. 2005;184:285-293.

17. Wu Y, Chen L, Scott PJ, et al. Mesenchymal stem cells enhance wound healing through differentiation and angiogenesis. Stem Cells. 2007;25:2648-2656.

18. Babensee JE, Mc Intire LV, Mikos AG. Growth factor delivery for tissue engineering. Pharm Res. 2000;17:497-504.

19. Werner S, Grose R. Regulation of wound healing by growth factors and cytokines. Physiol Rev. 2003;83:835-870.

20. Fréchette JP, Martineau I, Gagnon G. Platelet-rich plasmas: growth factor content and roles in wound healing. J Dent Res. 2005;84:434-439.

21. Barrientos S, Stojadinovic O, Golinko MS, et al. Growth factors and cytokines in wound healing. Wound Repair Regen. 2008;16:585-601.

22. Köveker GB. Growth factors in clinical practice. Int J Clin Pract. 2000;54:590-593.

23. Martí-Carvajal AJ, Gluud C, Nicola S, et al. Growth factors treating diabetic foot ulcers. Cochrane Database Syst Rev. 2015;10:CD008548.

24. Sommeling $\mathrm{CE}$, Heyneman AL, Hoeksema HE, et al. The use of plateletrich plasma in plastic surgery: a systematic review. J Plast Reconstr Aesthet Surg. 2013;66:301-311.

25. Schaffler A, Buchler C. Concise review: adipose tissue-derived stromal cells-basic and clinical implications for novel cell-based therapies. Stem Cells. 2007;25:818-827.

26. Gimble JM, Katz AJ, Bunnell BA. Adipose-derived stem cells for regenerative medicine. Circ Res. 2007;100:1249-1260.

27. Gimble JM, Guilak F. Adipose-derived adult stem cells: isolation, characterization, and differentiation potential. Cytotherapy. 2003;5:362-369.

28. Arita Y, Kihara S, Ouchi N, et al. Adipocyte-derived plasma protein adiponectin acts as a platelet-derived growth factor-BB-binding protein and regulates growth factor-induced common postreceptor signal in vascular smooth muscle cell. Circulation. 2002;105:2893-2898.

29. Nakagami H, Maeda K, Morishita R, et al. Novel autologous cell therapy in ischemic limb disease through growth factor secretion by cultured adipose tissue-derived stromal cells. Arterioscler Thromb Vasc Biol. 2005;25:2542-2547.

30. Kim WS, Park BS, Sung JH, et al. Wound healing effect of adipose-derived stem cells: a critical role of secretory factors on human dermal fibroblasts. J Dermatol Sci. 2007;48:15-24.

31. Sarkanen JR, Kaila V, Mannerstrom B, et al. Human adipose tissue extract induces angiogenesis and adipogenesis in vitro. Tissue Eng Part $A$. 2012;18:17-25.

32. Sarkanen JR, Ruusuvuori $\mathrm{P}$, Kuokkanen $\mathrm{H}$, et al. Bioactive acellular implant induces angiogenesis and adipogenesis and sustained soft tissue restoration in vivo. Tissue Eng Part A. 2012;18:2568-580. 
33. Yamaguchi DT. "Ins" and "Outs" of mesenchymal stem cell osteogenesis in regenerative medicine. World J Stem Cells. 2014;6:94-110.

34. Thanabalasundaram G, Arumalla N, Tailor HD, et al. Regulation of differentiation of mesenchymal stem cells into musculoskeletal cells. Curr Stem Cell Res Ther. 2012;7:95-102.

35. Shibata S, Tada Y, Asano Y, et al. Adiponectin regulates cutaneous wound healing by promoting keratinocyte proliferation and migration via the ERK signaling pathway. J Immunol. 2012;189:3231-3241.

36. Katz AJ, Llull R, Hedrick MH, et al. Emerging approaches to the tissue engineering of fat. Clin Plas Surg. 1999;26:587-603.

37. Hausman GJ, Richardson RL. Adipose tissue angiogenesis. J Anim Sci. 2004;82:925-934.

38. Oh DS, Cheon YW, Jeon YR, et al. Activated platelet-rich plasma improves fat graft survival in nude mice: a pilot study. Dermatol Surg. 2011;37:619925.

39. Jin R, Zhang L, Zhang YG. Does platelet-rich plasma enhance the survival of grafted fat? An update review. J Clin Exp Med. 2013;6:252-258.

40. Modarressi A. Platelet rich plasma (PRP) improves fat grafting outcomes. World J Plast Surg. 2013;2:6-13.

41. Salgarello $M$, Visconti $G$, Rusciani $A$. Breast fat grafting with platelet-rich plasma: a comparative clinical study and current state of the art. Plast Reconstr Surg. 2011;127:2176-2185.

42. Gentile P, Orlandi A, Scioli MG, et al. A comparative translational study: the combined use of enhanced stromal vascular fraction and platelet-rich plasma improves fat grafting maintenance in breast reconstruction. Stem Cells Transl Med. 2012;1:341-351.

43. Largo RD, Tchang LA, Mele V, et al. Efficacy, safety and complications of autologous fat grafting to healthy breast tissue: a systematic review. J Plast Reconstr Aesthet Surg. 2014;67:437-448.

44. Ueberreiter K, von Finckenstein JG, Cromme F, et al. BEAULI ${ }^{\mathrm{TM}}$ - a new and easy method for large-volume fat grafts. Handchir Mikrochir Plast Chir. 2010;42:379-385.

45. Sasaki GH. Water-assisted liposuction for body contouring and lipoharvesting safety and efficacy in 41 consecutive patients. Aesthet Surg J. 2011;31:76-88.

46. Araco A, Gravante G, Araco F, et al. Comparison of power water-assisted and traditional liposuction: a prospective trial. Aesthetic Plast Surg. 2007;31:259-265.

47. Schmolz M, Stein GM, Hubner WD. An innovative, centrifugation-free method to prepare human platelet mediator concentrates showing activities comparable to platelet-rich plasma. Wounds. 2011;23:171-182.

48. Galic S, Oakhill JS, Steinberg GR. Adipose tissue as an endocrine organ. Mol Cell Endocrinol. 2010;316:129-139.

49. Karastergiou K, Mohamed-Ali V. The autocrine and paracrine roles of adipokines. Mol Cell Endocrinol. 2010;318:69-78.

50. Gerhardt CC, Romero IA, Cancello R, et al. Chemokines control fat accumulation and leptin secretion by cultured human adipocytes. Mol Cell Endocrinol. 2001;175:81-92.

51. Bastard JP, Maachi M, Van Nhieu JT, et al. Adipose tissue IL-6 content correlates with resistance to insulin activation of glucose uptake both in vivo and in vitro. J Clin Endocrinol Metab. 2002;87:2084-2089.
52. Gupta V, Bains VK, Singh GP, et al. Regenerative potential of platelet rich fibrin in dentistry: literature review. Asian J Oral Health Allied Sci. 2011;1: 22-28.

53. Khiste SV, Tari RN. Platelet-rich fibrin as a biofuel for tissue regeneration. ISRN Biomaterials. 2013. Available at: http://dx.doi.org/10.5402/2013/ 627367

54. Lee JC, Kandula S, Sherber NS. Beyond wet-to-dry: a rational approach to treating chronic wounds. Eplasty. 2009;9:e14.

55. Dhillon RS, Schwarz EM, Maloney MD. Platelet-rich plasma therapy-future or trend? Arthritis Res Ther. 2012;14:1-10.

56. Kim WS, Mooney DJ, Arany PR, et al. Adipose tissue engineering using injectable, oxidized alginate hydrogels. Tissue Eng Part A. 2012;18:737743.

57. Lynch SE, Colvin RB, Antoniades HN. Growth factors in wound healing. Single and synergistic effects on partial thickness porcine skin wounds. J Clin Invest. 1989;84:640-646.

58. Kober J, Gugerell A, Schmid M, et al. Wound healing effect of conditioned media obtained from adipose tissue on human skin cells: a comparative in vitro study. Ann Plast Surg. 2016;77:156-163.

59. Keck M, Haluza D, Lumenta DB, et al. Construction of a multi-layer skin substitute: simultaneous cultivation of keratinocytes and preadipocytes on a dermal template. Burns. 2011;37:626-630.

60. Fu X, Fang L, Li H, et al. Adipose tissue extract enhances skin wound healing. Wound Repair Regen. 2007;15:540-548.

61. Li J, Qiao X, Yu M, et al. Secretory factors from rat adipose tissue explants promote adipogenesis and angiogenesis. Artif Organs. 2014;38:E33-45.

62. Mohamed-Ali V, Pinkney JH, Coppack SW. Adipose tissue as an endocrine and paracrine organ. Int J Obes Relat Metab Disord. 1998;22:1145-1158.

Cite this article as: Lopez J, Huttala O, Sarkanen J-R, Kaartinen I, Kuokkanen H, Ylikomi T (2016) Cytokine-rich adipose tissue extract production from water-assisted lipoaspirate: methodology for clinical use, BioResearch Open Access 5:1, 269-278, DOI: 10.1089/biores .2016 .0030 .

$\begin{aligned} & \text { Abbreviations Used } \\ & \mathrm{FGF} \beta=\text { fibroblast growth factor beta } \\ & \mathrm{G}-\mathrm{CSF}=\text { granulocyte colony stimulating factor } \\ & \mathrm{ATE}=\text { human adipose tissue extract } \\ & \mathrm{IGF}-1=\text { insulin-like growth factor } 1 \\ & \mathrm{IL}-6=\text { interleukin } 6 \\ & \mathrm{OR}=\text { operating room } \\ & \mathrm{PES}=\text { polyethylene sulfone } \\ & \mathrm{TNF} \alpha=\text { tumor necrosis factor alpha } \\ & \mathrm{VEGF}=\text { vascular endothelial growth factor }\end{aligned}$

